\title{
Whatever It Takes: Maintaining Student Engagement and Wellbeing in Unprecedented Times
}

\author{
Laura Burge \\ Student Experience and Engagement Manager \\ Angelica Klein-Boonschate \\ Campus Life Coordinator \\ Deakin Residential Services, Deakin University
}

\begin{abstract}
When COVID-19 impacted Australia earlier this year, student accommodation providers found themselves in the most challenging operating environment imaginable. Deakin Residential Services (DRS) rapidly adapted to the continually changing landscape, taking a 'whatever it takes' approach to supporting students across all four of Deakin University's campuses. Adopting a focus on ensuring members of our community were supported, engaged and informed, DRS instigated ongoing one on one welfare checks with every resident, and introduced a new wellbeing model tailored to support students through life 'out of the ordinary;' facilitated a comprehensive suite of virtual programs to foster community and responsibly engage students in a COVID-safe manner, and leveraged technology to keep students informed, manage expectations, and demonstrably ensure understanding, compliance and active support for key safety messages. This paper will share further details regarding this three-part strategy, exploring aspects which have been found to be silver-linings and likely to remain part of our operation post-pandemic, along with discussing some of the challenges and opportunities which have arisen throughout 2020. The authors will highlight key elements which are transferable, not only to other student accommodation providers, but also to those supporting the broader student experience within higher education.
\end{abstract}

\section{Keywords}

COVID-19, student accommodation, residence life program, student wellbeing

\section{Introduction}

Deakin Residential Services (DRS) provides a home to close to 3,000 residents across Deakin University's four campuses within the state of Victoria, Australia. Victoria has been subject to varying strict lockdown measures throughout the COVID-19 pandemic, which have included curfews, requirements for social distancing, and compulsory mask wearing. This also resulted in a complete cancellation of all face-to-face classes, lectures, events, activities and meetings, and the requirement for the vast majority of staff and students to study, teach and work from home where possible.

As the COVID-19 pandemic unfolded in 2020, in early March, DRS made the difficult decision to require residents to return home wherever possible, and without financial penalty. This direction excluded international students, those for whom Deakin was their primary residence, and other students finding themselves in exceptional circumstances. Whilst DRS remained open and operational throughout this time, and some students returned between lockdown stages due to easing restrictions, occupancy remained at approx. 30\% throughout the year.

Considering the significant impact upon students, student accommodation and the broader higher education sector, DRS adopted a focus on ensuring members of our residential community were supported, engaged and informed throughout 2020 (Aristovnik, Keržič, Ravšelj, Tomaževič and Umek 2020; Raaper \& Brown 2020; Tesar 2020; Son, Hegde, Smith, Wang \& Sasangohar 2020). This paper provides details regarding this three-part strategy, explores aspects which have been found to be silver linings and likely to remain part of our operation post-pandemic, discusses some of the challenges and opportunities which have arisen throughout this year, and in conclusion, highlights key elements transferable not only to other student accommodation providers, but to those supporting the broader student experience. 


\section{Supporting students}

Like many within higher education, the DRS team realised the gravity of COVID-19 early on, recognising the importance of placing student welfare above other organisational goals, and swiftly began re-imagining our approach to the residential student experience (Tinto 2003). This shift occurred in part from necessity, but also in order to acknowledge the reality that life really was out of the ordinary, not only for our student body, but for our staffing team.

In a standard year, DRS facilitates a student experience framework encompassing five pillars (Academic, Social and Community, Health and Wellbeing, Leadership, Arts and Culture). In 2020 however, we saw the need to create and implement a temporary wellbeing and experience model that reflected the completely revised landscape, adopted an 'ethos of caring,' and which drew attention and focus to three key priorities (Aristovnik et al 2020; Son et al 2020; Tinto 2003).Our 'Belong, Balance, Broaden' approach

Figure 1) was designed to:

- Foster students sense of belonging and engagement with our residential community,

- Encourage students to balance mind and body, and,

- Enable students to explore opportunities to broaden their horizons through virtual personal and professional development activities, webinars and workshops.

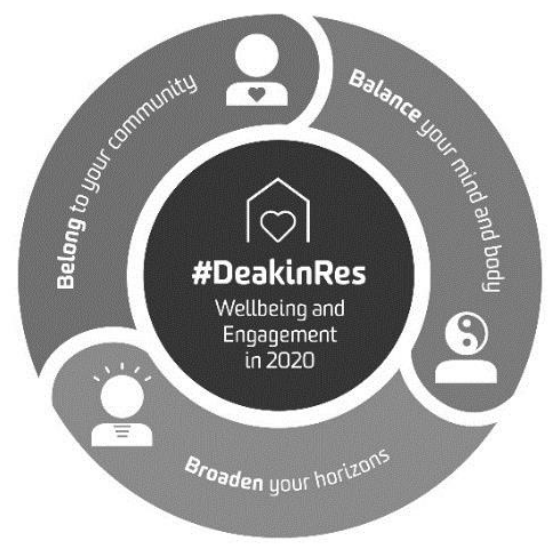

Figure 1: Deakin Res Belong, Balance, Broaden Framework

In addition to this revised approach to student experience and programming, one of the most important new initiatives implemented during this time involved the introduction of monthly welfare checks via phone and/or email for every resident who remained on site. By connecting on a regular basis, our Campus Life staff were able to ensure residents were provided with key information, timely access to additional support services, had a friendly, albeit virtual, face to raise any concerns or problems, and ultimately, felt individually supported and valued throughout an extremely difficult and challenging period (Cheng 2004; Cooper 2009; Jacklin 2007; Kift, Nelson \& Clarke 2010; Son et al 2020; Tinto 2003).

\section{Engaging students}

Effectively engaging residents in community programming to support their wellbeing, connectedness and sense of belonging was DRS' second key priority throughout this unusual year (Cheng 2004; Coates \& Ransom 2011; Cooper 2009; Glaser, Hall \& Halperin 2006; Kift, Nelson \& Clarke 2010). As was the case across the sector, in March the entire pre-planned calendar of face-to-face student experience events were cancelled as a result of COVID-19 and State Government social distancing 
requirements. As a result, DRS pivoted to a virtual space, offering a daily program of online events and activities intended to meet the diverse and changing needs of our entire cohort (Cheng 2004; Coates \& Ransom 2011; Son et al 2020). Programs were hosted within existing private social media groups with residents and varied in style, scale and required level of involvement and input, based on awareness that students were in the midst of complete upheaval - transitioning to online learning, isolation from friends and family, and generally adjusting to life in lockdown.

Whilst levels of engagement understandably wavered over time, some of our most popular activities included Meme Monday, Tik Tok Tuesday, and Trivia Thursday, and over the course of the academic year, the team coordinated over four hundred digital events and activities. Volunteer peer student leaders were heavily involved throughout, not only providing regular feedback on the efficacy of each program, but also taking frequent responsibility for facilitation of various events. This peer involvement and leadership has been critical in role modelling the value of engagement and involvement in residential life to our general cohort, and in facilitating social connections, friendships and support networks amongst students facing similar circumstances (Glaser, Hall \& Halperin 2006; Jacklin 2007; Peregrina-Kretz, Seifert, Arnold \& Burrow, 2018; Shook \& Keup 2012). Virtual program offerings were also accompanied by limited and COVIDSafe face to face door drops of food items and activity packs. This initiative was particularly well received by our community who were craving any kind of face-to-face interaction.

\section{Informing students}

Our final strategy, and of obvious importance during a crisis of any kind, was ensuring our residents were kept regularly informed and updated throughout the ever-changing levels of restrictions and lockdown (Northam 2017). In addition to standard official forms of communication (primarily email and social media), DRS utilised WebinarJam, a technological platform to present key information to our in-room residents in an interactive, engaging, timely and effective manner via compulsory online monthly community meetings. As part of this initiative, all residents were required to attend live briefings provided by Campus Life staffing teams, accompanied by our student leaders. Sessions were recorded to enable students to watch on-demand if they were unable to make the live event. In addition to enabling a professional style of presentation, the platform provided the ability for attendees to ask questions (verbally or through live chat), answer polls, watch videos and view slides, resulting a dynamic and engaging communication tool. A significant and unintended benefit of the initiative proved to be the ability to track attendance and compliance, ultimately saving hours of administration which had previously taken place manually using spreadsheets.

\section{Evaluating success}

Whilst the DRS team believed that our three-part strategy had been effective in supporting students during COVID, student feedback was also gathered to validate these claims. In a standard year DRS conducts an Annual Residential Student Experience Survey in August, and in 2020 this survey was modified with additional questions added to reflect the COVID impacted landscape. Somewhat surprisingly perhaps, we had a very impressive response - our highest yet in four years with 52\% completion, though admittedly from a smaller cohort. There are several results from the survey which are worthy of highlighting (Table 1).

In providing qualitative feedback, one resident noted, “...living on campus [during COVID] has had a positive impact on my mental health...I have been afforded the opportunity to stay close to those in a situation similar to mine while social distancing and have had the support of Reception and Campus Life [staff] to back me up throughout." Another stated, “...Res has provided a very safe and welcome environment to stay throughout this year. It has also helped my decision on whether to return to my home country or not. I believed that living on campus is a safe option and chose to stay here." 
Table 1

Level of agreement with COVID-safe measures

\begin{tabular}{lll} 
Level of Agreement & $\begin{array}{l}\text { \% Strongly } \\
\text { disagree or } \\
\text { disagree }\end{array}$ & $\begin{array}{l}\text { \% Agreed or } \\
\text { strongly } \\
\text { agreed }\end{array}$ \\
\hline $\begin{array}{l}\text { I feel that Deakin Residential Services has proactively managed COVID } \\
\text { risks in the residences }\end{array}$ & $5 \%$ & $95 \%$ \\
I feel that COVID-safe measures had been well communicated to me & $4 \%$ & $96 \%$ \\
$\begin{array}{l}\text { I understand what I can do to help ensure the residential environment is } \\
\text { COVID-safe for me and others }\end{array}$ & $1 \%$ & $99 \%$ \\
I feel that student accommodation is a safe place to live during COVID & $5 \%$ & $95 \%$
\end{tabular}

Perhaps the results of which our Campus Life teams were most proud however, was the fact that $92 \%$ of survey respondents were satisfied or very satisfied with the virtual program offering - an impressive statistic in light of the challenges associated with digital fatigue during this time. Additionally, $97 \%$ of respondents reported a positive interaction with a staff member this year, no mean feat when staff were frequently passing on bad news like additional restrictions or curfews. This statistic particularly validates the incredible work of staff who went above and beyond in ensuring students had the best possible experience during a very difficult and challenging year.

\section{Challenges}

Whilst there have been successful elements of DRS' approach to supporting students during COVID, it hasn't been completely smooth sailing. There were three main types of challenges faced throughout 2020, many of which will resonate with others working within student support services and student accommodation.

Firstly, the sheer scale and impact of the disruption caused by COVID-19 (Aristovnik et al 2020; Raaper \& Brown 2020; Tesar 2020). Whilst this looked different at ground level across the sector, student accommodation providers faced one challenge after the other, introducing new policies, frameworks and guidelines regarding occupancy, physical distancing and use of communal facilities, only to be compelled to update, revise or completely overhaul and communicate new versions mere weeks, sometimes days, later. This has proven challenging, confusing and frustrating for staff, who have had to reinvent experience plans and event programming usually planned months in advance overnight, but more importantly for our residents, who not only have been impacted by changes to their learning, but also their living environments.

Secondly, whilst student wellbeing has been a key priority throughout the various stages of lockdown, as we've all become aware only so much virtual programming can be of genuine benefit when students are under strict lockdown conditions. Indeed, students may be struggling with stress and anxiety, financial difficulties, increased academic workload, further exacerbated through isolated from family, friends and life as we previously knew it (Raaper \& Brown 2020; Son et al 2020). An easing of restrictions followed by a return to lockdown, particularly for our Melbourne based residents, also proved challenging. Engagement as such has understandably wavered over time with students struggling with remote learning and online fatigue. Digital expertise - or lack thereof - has also been a factor. The bulk of work in a standard year for our Campus Life staff revolves around oncampus event programming, student meetings and frequent face to face to engagement, and whilst we've all had to learn the ropes of Zoom and Microsoft Teams, creating engaging online events, and designing eye-catching promotional social media posts using new - and sometimes quite complicated - technology has had its challenges. Practice has helped make things 'somewhat perfect,' but it has certainly been problematic at times, particularly when resources are stretched and there are competing - and frequently changing - priorities. 
Finally, whilst we, like many others, developed and rolled out creative and innovative virtual student experience programs, welfare checks and food drops, there are obvious limitations to authentic community building in purely virtual forums. Students craved face-to-face contact, even in severely restricted formats. Determining effective ways to engage students in upcoming events and activities, foster a sense of affinity and belonging, connect them with their community, and proactively provide support in these new online spaces remains an ongoing concern.

\section{Silver linings}

Challenges aside, there have been a number of silver linings from some of the initiatives that have resulted from the impact of COVID-19, including a shift towards greater cross campus collaboration, application of innovative technology, and engagement of unique student cohorts within our residential community. Borne initially from necessity, DRS' unified approach has resulted in the effective pooling of resources and staff, centralised communication, and facilitation of virtual events and programs for all, regardless of campus location. This has further resulted in a borderless residential community, enabling our students to interact, collaborate and engage with others' that they might never have met in pre-COVID times based on campus boundaries. The application and use of innovative technology, in particular our webinar program for community gatherings, had the benefit of inadvertently enhancing our administrative processes, communicating key messages more effectively and saving hours of time previously spent manually recording and managing attendance records. Our new virtual programs, whilst not without their challenges, have also attracted unique student cohorts, many of whom might not have engaged in some of our traditional face to face activities or events. External to DRS, we've also been overwhelmed and incredibly grateful to the global community for the amount of accessible content which has been shared by our colleagues and by organisations for the benefit of all. Never before have we been able to source international speakers and facilitators, seek advice, share examples of best practice, or access such valuable resources as we have during this year.

\section{Transferable lessons}

There have been a number of lessons learnt in supporting our residents in response to COVID which are transferable not only to other student accommodation providers, but to those operating in the broader student life and university context. Firstly, a significant component of our effective response was due to the unwavering determination of our priorities very early on. We were very clear with staff, the broader University and our governing Board that the safety, wellbeing and experience of our residents was a priority above all else, and this commitment guided our entire response to the COVID crisis as it unfolded. Secondly, upfront acknowledgement of life out of the ordinary, via the introduction of our tailored student experience and wellbeing model, a revised program of virtual offerings, and the implementation of regular welfare checks, played a large role in ensuring our residents felt supported, engaged, informed and perhaps more importantly, in control, at a time when their world was spontaneously combusting around them. Third, the pace at which we were able to implement these changes, including relocating residents to ensure social distancing and directing those that could, to return home without penalty, demonstrated that student safety and the student experience was front of mind - despite the financial ramifications. Fourth, critical to our success this year was investing time and resources into technology which met our completely revised organisational requirements. As noted, this had the benefit of inadvertently enhancing our administrative processes, but more importantly, enabled and empowered our staff and students to connect and collaborate in virtual settings. Finally, as has become so essential across every aspect of the work undertaken in higher education, our student leaders were involved throughout as co-creators and promoters of the raft of virtual programs we introduced, role models for COVIDSafe behaviours and key crisis communications. 


\section{Conclusion}

2020 has undoubtedly been a year unlike any other. Despite the challenges the sector has faced, staff across the industry, including those within DRS, have worked tirelessly to support, engage, and inform students to ensure they have had the best possible experience during a very difficult period. It is our students, however, who perhaps deserve greater recognition, showing remarkable resilience in adapting to online learning, remote engagement, and the complete upheaval of their best laid plans. However, it is worth noting, as Malala Yousafzai, female rights activist recently tweeted - "...the class of 2020 won't be defined by what we lost to this virus, but by how we responded to it (Adams 2020)." 


\section{References}

Adams, S. (2020, May 16). The best commencement speeches of 2020. Forbes. https://www.forbes.com/sites/susanadams/2020/05/16/the-best-commencement-speeches-of-2020/

Aristovnik A, Keržič D, Ravšelj D, Tomaževič N, Umek L. (2020). Impacts of the COVID-19 pandemic on life of higher education students: A global perspective. Sustainability. 12(20), 8438, https://doi.org/10.3390/su12208438

Cheng, David, X. (2004). Students' sense of campus community: What it means, and what to do about it. NASPA Journal, 41(2), 216-234, https://doi.org/10.2202/1949-6605.1331

Coates, H. \& Ransom, L. (2011). Dropout DNA, and the genetics of effective support, AUSSE Research Briefings, 11. Retrieved from http://research.acer.edu.au/cgi/viewcontent.cgi?article=1000\&context=ausse

Cooper, R. (2009). Constructing Belonging in a diverse campus community. Journal of College and Character, 10(3). https://doi.org/10.2202/1940-1639.1085

Glaser, N., Hall, R., \& Halperin, S. (2006). Students supporting students: The effects of peer mentoring on transition, belonging and retention amongst first year university students, Australian and New Zealand Student Services Association, 27, 4-19. Retrieved from https://www.researchgate.net/publication/236582329_ Students_supporting_students_The_effects_of_peer_mentoring_on_the_experience_of_first_year_university_s tudents

Jacklin, A. (2007). What is meant by 'support' in higher education? Towards a model of academic and welfare support. Journal of Research in Special Education Needs, 7(2), 114 - 123, https://doi.org/10.1111/j.14713802.2007.00087.x

Kift, S., Nelson, K. \& Clarke, J. (2010). Transition pedagogy: A third generation approach to FYE - A case study of policy and practice for the higher education sector. The International Journal of the First Year in Higher Education, 1(1), 1-20, https://doi.org/10.5204/intjfyhe.v1i1.13

Northam, A. L. (2017). Crisis communication in higher education. Leadership Education Capstone Papers, 10. Retrieved from https://openriver.winona.edu/leadershipeducationcapstones/10

Peregrina-Kretz, D, Seifert, T, Arnold, C \& Burrow, J. (2018). Finding their way in post-secondary education: the power of peers as connectors, coaches, constructors and copycats, Higher Education Research and Development, 37(5), 1076 - 1090, https://doi.org/10.1080/07294360.2018.1471050

Raaper, R. \& Brown, C. (2020). 'The Covid-19 pandemic and the dissolution of the university campus: implications for student support practice.' Journal of Professional Capital and Community, https://doi.org/10.1108/JPCC-062020-0032

Shook, J.L. \& Keup, J.R. (2012). The benefits of peer leader programs: An overview from the literature, New Directions for Higher Education, 157, (Spring), 5-16. https://doi.org/10.1002/he.20002

Son, C, Hegde. S, Smith, A, Wang, X, Sasangohar, F. (2020). Effects of COVID-19 on college students' mental health in the United States: interview survey study, Journal of Medical Internet Research, 22(9) https://dx.doi.org/10.2196/21279

Tesar, M. (2020). Towards a post-covid-19 'New normality?' Physical and social distancing, and the move to online and higher education, Policy Futures in Education, 18(5) 556 - 559, https://doi.org/10.1177\%2F1478210320935671

Tinto, V. (2003). The dimensions of institutional action. In Leaving college (2nd ed., pp. 138 - 203). The University of Chicago Press.

The authors may be contacted via

1.burge@deakin.edu.au

\section{Please cite this paper as:}

Burge, L. \& Klein-Boonschate, A. (2021). Whatever it takes: Maintaining student engagement and wellbeing in unprecedented times. Journal of the Australian and New Zealand Student Services Association, 29(1), 52-58.

https://doi.org.10.30688/janzssa.2021.1.04 